\title{
A RESEARCH ON THE RELATIONSHIP BETWEEN THE SECTION OF UNIVERSITY STUDENTS AND CAREER ADAPTABILITY
}

DOI: 10.17261/Pressacademia.2018.884

PAP- V.7-2018(37)-p.217-222

\section{Vasfi Kahya ${ }^{1}$, Esin Ceylan ${ }^{2}$}

${ }^{1}$ Dumlupinar University, Kutahya, Turkey.

vasfi.kahya@dpu.edu.tr, ORCID: 0000-0002-2154-5689

${ }^{2}$ Selcuk University, Konya, Turkey.

esinceylan@selcuk.edu.tr, ORCID: 0000-0002-4566-0542

To cite this document

Kahya, V., Ceylan, E. (2018). A research on the relationship between the section of university students and career adaptability. PressAcademia Procedia (PAP), V.7, p.217-222.

Permemant link to this document: http://doi.org/10.17261/Pressacademia.2018.884

Copyright: Published by PressAcademia and limited licenced re-use rights only.

\section{ABSTRACT}

Purpose- It is aimed to support individual career adaptability with the knowledge and experience gained in university education. The purpose of this study is to determine the relation between the departments and the demographic variables that university students have and that carrer adaptablities.

Methodology- The reseach population is composed of students who attend vocatinal collages affiliated to Dumlupınar University. The face to face survey method was used to determine the relationship between students' departments and demographic variables and career adaptability. "Personal Information Form" prepared by researchers and "Career Adaptabiliity Scale" developed by Savickas and Profel and adapted to Turkish by Kanten (2012) was used to determine the demographic characteristics of the participants in the research data. Career adaptability scale is divided into 4 sub-dimensions. These dimentios are anxiety, control, curiosity and trust.

Findings- As a result of the analyzes made, differences between carrer adaptability and gender and income of students were found.

Conclusion- In addition, it was concluded that the results of the anxiety and trust sub-dimension of the students' preffered departments and career adjustment abilities also differed.

Keywords: University student, carrer, carrer adaptability.

JEL Codes: 120, 121, 129

\section{ÜNIVERSITE ÖĞRENCILERININ BÖLÜMLERI ILE KARIYER UYUM YETENEKLERI ARASINDAKI íLiŞKIYi BELIRLEMEYE YÖNELIK BIR ARAŞTIRMA}

\section{ÖZET}

Amaç- Üniversite eğitiminde kazanılan bilgi ve deneyimlerle bireysel kariyer uyum yeteneklerinin desteklenmesi amaçlanmaktadır. Bu çalışmanın amacı da üniversite öğrencilerinin eğitim aldıkları bölüm ve sahip oldukları demografik değişkenler ile kariyer uyum yetenekleri arasındaki ilişkiyi belirlemektir.

Yöntem- Araştırma evrenini, Dumlupınar Üniversitesi'ne bağlı meslek yüksekokullarında öğrenim gören öğrenciler oluşturmaktadır. Öğrencilerin bölümleri ve demografik değişkenleri ile kariyer uyum yetenekleri arasındaki ilişkiyi belirlemek için yüz yüze anket yöntemi uygulanmıştır. Araştırma verilerinin elde edilmesinde katılımcıların demografik özeliklerini belirlemek için araştırmacılar tarafından hazırlanan "Kişisel Bilgi Formu" ve Savickas ve Profel (2012) tarafından geliştirilen ve Kanten (2012) tarafından Türkçeye uyarlanan "Kariyer Uyum Yetenekleri Ölçeği" kullanılmıştır. Kariyer uyum yetenekleri ölçeği 4 alt boyuta ayrılmaktadır. Bu boyutlar ise kaygı, kontrol, merak ve güvendir.

Bulgular- Yapılan analizler sonucunda ise kariyer uyum yetenekleri ile öğrencilerin cinsiyetleri ve gelirleri arasında farklılık bulunmuştur. Sonuç- Ayrıca öğrencilerin tercih ettikleri bölümler ile kariyer uyum yeteneklerinin kaygı ve güven alt boyutlarının da farklılık gösterdiği sonucuna varılmıştır.

Anahtar Kelimeler: Üniversite öğrencisi, kariyer, kariyer uyum yeteneği.

JEL Kodları: 120, 121, 129 


\section{Giriş}

Günümüzde, genç bireyler kariyer konusuna oldukça fazla önem vermektedirler. Bu bağlamda bireyler küçük yaşlardan itibaren çalışma hayatına ilişkin geleceklerine yönelik olarak meslek belirleme aşamasında çaba içerisindedirler. Ancak, meslek seçimi uzun bir süreçtir. Meslek seçimi ve buna bağlı olarak kariyer hedefinden önce bireyin kendini iyi tanıması, ilgi alanlarını ve yeteneklerini keşfetmesi gerekmektedir. Bireyler meslek seçimi yaptıktan sonra kariyer hedeflerini gerçekleştirebilmek için bu alanda eğitim almak üzere üniversitelerde bölüm tercihi yapmaktadırlar. Eğitim hayatı sonrası için de bireyin kariyer planlaması önem kazanmaktadır. Çünkü bireyin "kendini gerçekleştirmesi" kariyer sürecinin başlangıç noktasını oluşturmaktadır.

Kariyer planlaması, bireyin öz değerlendirme yaparak güçlü ve zayıf yönlerini tespit etmesi, ilgisine, bilgisine ve yeteneklerine yönelik kariyer hedeflerini oluşturması ve bu hedeflere ulaşabilmek için faaliyet planları geliştirmesidir (Dündar, 2013: 270). Genç bireyler eğitim sürecinde ve sonrasında çalışma hayatına başlarken hızla değişen bir iş piyasasıyla karşı karşıya kalmaktadır. Bireylerin almış oldukları mesleki alanda ki eğitim ile bu alana karşılık gelen işi bulma arasındaki ilişki zayıf olabilmektedir. Bireyler büyük bir belirsizlikle karşılaşmakta ve bu nedenle umutlarını ve beklentilerini kariyer hayatlarının başında yeni koşullara göre uyum sağlamak zorunda kalmaktadırlar (Vianen vd., 2012:1). Bireylerin, kariyer tercihi sürecinde doğru seçim yapabilmesi için yaratıcılık, rekabet, iş yaşam dengesi, iş disiplini, işe bağıılık, ücret, sosyal imkânlar, başarılarının ödüllendirilmesi, işyerindeki eğitim imkânları, kişiler arası iletişim, serbestlik ve bağımsız çalışabilme, değer yargıları gibi çeşitli konuları dikkate almaları iş yaşamına uyum sağlama sürecinde, yaşayacağı sorunları azaltmaktadır (Erdoğan,2008;164). Bu bağlamda bireylerin yeni koşullara uyum sağlama süreci yaşam boyu öğrenme ile desteklenebilmektedir. İstihdam edildikten sonra da bireyin kariyer uyum yeteneklerinin geliştirilmesi iş hayatlarında başarı sağlamaktadır. Aksi takdirde birey ve kariyer uyumu sağlanamadığında iş hayatı başarısızlıkla sonuçlanmaktadır.

\section{LITERATÜR INCELEMESI}

Kariyer kavramı, Latin kökenli olan ve bir yol veya araç/taşıma yolu anlamına gelen "carraria"dan türemiştir (Arthur ve Lawrence, 1984:1). Kariyer kavramı ilk kez 1970'li yıllarda incelenmeye başlamıştır. Genel alamda kariyer, bireylerin hayatları boyunca sürdürdüğü uğraşı açıklamaktadır. Özel anlamda ise genç bireylerin iş hayatında ilerleme ve yükselme beklentisi ile başlayan ve emekliliğe kadar geçen süre içerisinde ki uğraşı ifade etmektedir (Yazıcı, 1987:29). Kariyer, "bir meslekte zaman ve çalışmayla elde edilen aşama, başarı ve uzmanlık" (TDK, 2018), başka bir tanıma göre "bireyin hayatı boyunca iş ile ilgili edindiği tecrübeler"i oluşmaktadır. (Decenzo ve Robbins, 1996:266). Maanen ve Schein (1977) ise, kariyeri "hepimizin sahip olduğu ama çoğu zaman fark etmediğimiz bir değer" olduğunu ve herkesin yaşamları boyunca geçirdiği deneyim ve maceralardan oluştuğunu açıklamaktadırlar (Akt: Woodd, 1999:24).

Kariyer seçimi ise bireyin hayatında ki en önemli kararlardan biridir. Bu kararı verirken çeşitli faktörleri göz önüne alarak iyi düşünmek gerekir çünkü bu karar genellikle hayatta bir defa verilir (Perkmen, 2009:119). Kariyer seçiminde ve bu sürecin oluşumunda bireyi etkileyen çeşitli içsel ve dışsal faktörler bulunmaktadır. Kişilik, bu süreçte bireyi yönlendiren en önemli içsel faktördür. Aynı zamanda bir diğer içsel faktör olan bireyin kendini gerçekleştirme güdüsü de kariyer seçimi ve sürecini etkilemektedirler. En önemli dışsal faktör ise bireyin sosyal özgeçmişidir. Zaman içerisinde bu faktörler bireyi yönlendirerek kariyer kararını etkilemektedir (Öge ve Karasoy, 2016:147). Bireyler, sahip oldukları becerileri geliştirme imkânı sunan mesleği seçmesi durumunda başarı kazanmakta ve daha nitelikli eleman haline gelmektedir. Bu bağlamda özellikle üniversiteler genç bireylere ilgi alanlarına yönelik doğru rehberlik sağladıklarında, daha yüksek nitelikli ve motivasyona sahip çalışanlar haline gelmektedirler. Doğru meslek seçimi, bireyleri motive etmekte ve yaptıkları işten zevk almalarını sağlamaktadır (Arpat ve Yeşil, 2017:182). Bu bağlamda bireyin kişisel özellikleri ile kariyer uyum yeteneği önem kazanmaktadır.

Kariyer süreci inişleri çıkışları olan bir yol gibidir. Bireylerin bu süreçte kariyerinde ki başarısı değişimlere sağladığı uyuma bağlıdır. Kariyer süreçlerindeki değişime uyum sağlamak bireylerin yetenekleri ile ilgilidir. Bu nedenle, bireylerin kariyer başarısı da “Kariyer Uyum Yeteneği" olarak adlandırılan kavram ile açıklanmaktadır (Kavi ve Kaya, 2018:106). Zikic ve Klehe (2006) kariyer uyumluluğunu, iki şekilde ele almaktadır. Bunlar kariyer keşfi ve kariyer planlamasıdır. Kariyer keşfi, bireyin kendini ve mesleğini tanımasıdır. Kariyer planı ise, bireyin geleceğini düşünmesi ve geleceğe dönük amaçları belirlemesidir. Kariyer uyum yeteneği, bireylerin öngörülebilen görevlere hazırlanarak, işte ve çalışma koşullarında tahmin edilemeyen değişikliklerin üstesinden gelmeye hazır olmalarıdır (Savickas, 1997:254). Kariyer uyum yetenekleri; "kaygı", "kontrol”, "merak" ve "güven” boyutlarında oluşmaktadır. Kaygı, bireylerin mesleki gelecek için yeteneklerinin farkında olmasına ve buna yönelik planlan yapmalarına dayanmaktadır. Kontrol, bireylerin mesleki gelecekleri ile ilgili karar verebilme ve kendi kendilerini yönetebilme yeteneğine sahip olmalarıyla ilgilidir. Merak, bireyin çevresine yönelik araştırma eğilimi ifade etmektedir. Güven ise, bireylerin kariyerlerinde karşılaşabilecek sorunları çözmeye yönelik kendilerini yeterli görmelerini açıklamaktadır (Savickas ve Porfeli, 2012:663). Bireylerin kariyer uyum sürecinde, öz farkındalık, mesleki farkındalık, destek (aile, çevre gibi), iş yaşam dengesi gibi çeşitli faktörler de önemli olmaktadır. Aynı zamanda, bireylerin hayatlarında karşılaştıkları yeni durumlarla baş etmede sahip oldukları iyimserlik eğilimleri ile uyum süreçleri arasında da ilişki kurulabilmektedir (Zorver ve Owen, 2014:316-317).

Son yıllarda üniversite öğrencilerinin kariyer uyum yetenekleri ile ilgili yapılan çalışmalar incelendiğinde şu sonuçlara varılmıştır. Kavi ve Kaya (2018)'in İstanbul'da devlet ve vakıf üniversitelerinde öğrenim gören öğrencilerinin kariyer uyum yeteneklerinin sahip oldukları demografik veriler ile ilişkisini incelemiş oldukları çalışmalarında öğrencilerin cinsiyet, yaş, barınma şekli ve bulundukları sınıf düzeyi ile kariyer uyum yetenekleri arasında anlamlı bir fark ortaya çıkmıştır. Mercan (2016)'ın psikolojik sermayenin kariyer uyum yeteneği ile ilişkisine yönelik yapmış olduğu araştırmasında, psikolojik sermaye ile kariyer uyum yeteneği özellikleri arasında anlamlı bir ilişki olduğu sonucuna varılmıştır. Genç (2016)'in, öğrencilerin kişisel gelişim yönelimlerinin kariyer uyum yeteneklerine etkisi belirlemeye yönelik yapmış olduğu çalışmasında, öğrencilerin kişisel gelişim yönelimlerinin kariyer uyum yeteneklerine güçlü bir etkisi olduğu sonucuna varılmıştır. Çelik (2017)'in, eleştirel düşünme becerilerinin kariyer uyum yeteneklerine etkisini belirlemek için öğrencilere yapmış olduğu çalışmada, eleştirel düşünme eğilimi yüksek olan bir bireyin kariyer uyum yeteneğinin de yüksek olduğu sonucuna varılmıştır. 


\section{VERI VE YÖNTEM}

\subsection{Araştırmanın Amacı ve Önemi}

Araştırmanın amacı katılımcıların tercih ettiği bölümlerin kariyer uyum yetenekleri üzerinde etkisini ve bu iki değişken arasında ilişkiyi test etmektir. Bunun yanında katılımcılara kişisel bilgiler ile ilgili değişkenlere ve buna bağlı olarak kariyer uyum yeteneği davranışlarının farklılaşıp farklılaşmadığını incelemeyi amaçlamaktadır. Her bireyin kariyer planı farklı olmaktadır. Fakat okul sonrası herkes istediği şartlara sahip bir işi bulma imkanına sahip olamayabilir. Bu durum, bulunan işe uygun bir çalışan olmanın önemini ortaya çıkarmaktadır. Özellikle kuşak farkları $(X, Y, Z)$ insan kaynakları yönetimi açısından dikkate alınması gereken bir konudur. Kuşak farklılığından kaynaklı özelliklerin bilinmesi kariyer planlamasında daha iyi sonuçlar elde edilmesi için avantaj olarak kullanılabilir. Zira $Y$ ve $Z$ kuşağı hızlı reaksiyon gösterebilen değişime açık bireyler oluşu, kariyer uyum yetenekleri konusunda da avantajlı olabileceği yönünde araştırmalar da fikir vermektedir. Bu gerekçelerden dolayı bireylerin tercih ettikleri bölümlerin onların kariyer uyum yetenekleri konusunda bir etkiye sahip olup olmadığıı bilmek bu avantajı değerlendirmek adına önemli olacaktır.

\subsection{Araştırmanın Evreni ve Örneklemi}

Araştırmanın örneklemi Dumlupınar üniversitesine bağlı meslek yüksekokullarında okuyan İşletme Yönetimi, Halkla ilişkiler ve Yerel Yönetimler bölümlerinden oluşmaktadır. Araştırmada basit tesadüfi örneklem yöntemi kullanılmıştır. Araştırmaya katılan 422 kişiden anket yöntemi ile cevaplar alınmıştır.

\subsection{Veri Toplama Yöntemi ve Kullanılan Ölçekler}

Araştırmanın verilerinin toplanması için hazırlanmış olan anketten faydalanılmıştır. Anket formu iki bölümden meydana gelmiştir. Birinci bölümde katılımcılara ait demografik özellikler sorulmuş, ikinci bölümde ise kariyer uyum yeteneği ile ilgili sorular sorulmuştur. Kariyer uyum yeteneği ile ilgili sorular ise Savickas ve Profeli'nin (2012) çalışmasında kullanılan ve Kanten (2012) tarafından Türkçe geçerlilik ve güvenilirliği yapılan 13 ülkeden 18 araştırmacının ortak çalışması sonucu hazırlanan "kariyer uyum yetenekleri ölçeği" kullanılmıştır. Orijinal çalışmada 4 alt boyut ve 24 ifade bulunmaktadır. Bunlar kaygı, kontrol, merak ve güven boyutlarıdır. Türkçe uyarlamasında ise 19 ifade ve 4 boyut (kaygı- $\alpha=.61$, kontrol- $\alpha=.77$, merak- $\alpha=.79$ ve güven- $\alpha=.81$ ) olarak araştırmalarda kullanılabileceği ifade edilmiştir.

Elde edilen veriler daha sonra istatistik programı yardımı ile test edilmiştir. Yapılmış olan anketlerde kayıp değerler ise ortalama değer atama yöntemi ile giderilmiştir. Kariyer uyum yeteneği soruları faktör analizine tabi tutulmuştur. Daha sonra T-testi, Anova analizi yapılmıştır.

\subsection{Araştırmanın Hipotezleri}

Araştırmanın hipotezleri aşağıdaki gibidir:

H1: Araştırmaya katılan katılımcıların kariyer uyum yetenekleri, tercih ettiği bölüme göre anlamlı bir farklılık göstermektedir.

H2: Araştırmaya katılan katılımcıların kariyer uyum yetenekleri gelir düzeyine göre anlamlı bir farklılık göstermektedir.

H3: Araştırmaya katılan katılımcıların kariyer uyum yetenekleri, cinsiyete göre anlamlı bir farklılık göstermektedir.

\section{BULGULAR}

Araştırmaya katılan üniversite öğrencilerinin demografik özellikleri, çalışmanın amacına uygun olarak belirlenen ölçek soruları ve hipotezleri test etmek amacıyla yapılan analizler aşağıda yer almaktadır.

\subsection{Demografik Bulgular}

Katılımcıların demografik değişkenlerine ilişkin tanımlayıcı istatistikleri Tablo 1'de yer almaktadır

Tablo 1: Katılımcıların Demografik Özelliklerine ilişkin Bulgular

\begin{tabular}{l|ll} 
Demografik Değişkenler & N & \% \\
Cinsiyet & 218 & 54,5 \\
Kız & 204 & 45,5 \\
Erkek & 192 & \\
Tercih Ettiği Bölüm & 124 & 45,4 \\
İşletme Yönetimi & 106 & 29,3 \\
Halkla Ilişkiler & & 25,1 \\
Yerel Yönetimler & 71 & 16,8 \\
Gelir Durumu & 113 & 26,9 \\
1603 TL ve altı & 150 & 35,5 \\
1604 - 2000 TL & 88 & 20,8 \\
2001 - 3000 TL & &
\end{tabular}


Tablo 1 incelendiğinde toplam 422 kişi araştırmaya katılmıştır. Katııımcıların cinsiyet dağııımında kız ve erkek öğrenciler arasında eşitlik görülebilmektedir. Tercih edilen bölümlere göre bakıldığında ise \% 45 'ini işletme yönetimi bölümü öğrencileri oluşturmaktadır. Yaklaşık \%30 ile Halkla ilişskiler ve \%25 ile de Yerel Yönetimler bölümü öğrencileri katılmışıı. Gelir durumu açısından ise 2001 ile 3000 TL gelire sahip olanlar en kalabalık grubu oluşturmaktadır. Genel olarak diğer gruplara bakıldığında ise dengeli sayılabilecek bir dağıım gözükmektedir.

\section{Faktör ve Güvenilirlik Analizleri}

Üniversite öğrencilerinin eğitim aldıkları bölüm ve sahip oldukları demografik değiş̧kenler ile kariyer uyum yetenekleri arasındaki ilişkiyi belirlemek amacıyla yapılan bu çalışmada kullanılan ölçeğin boyutlarını belirlemek için faktör analizi ve güvenilirlik düzeyini test etmek için de Cronbach Alpha güvenilirlik anallizleri yapılmışıı. Analiz sonuçları Tablo 2'de yer almaktadır.

Kariyer uyum yeteneği ölçeğinde yer alan ifadelerin faktör analizine uygunluğunu belirlemek için KMO Örneklem Yeterlilik Testi ve Barlett's küresellik testleri yapılmıştır. KMO sonucunun 0,8 ile 0,89 arasında değer alması çok iyi olarak değerlendirilmektedir (Aydın, 2007: 5). Bu çalışmada KMO örneklem yeterlilik değeri ,814; Barlett küresellik testi 2745,265; serbestlik derecesi 159 bulunmuştur. Anlamlılık düzeyi (pi) 0,00 bulunmuş olup bu değer 0,05 'den küçük olduğu için veri seti faktör analizi yapmaya uygundur.

\section{Tablo 2: Faktör ve Güvenilirlik Analizi Sonuçları}

\begin{tabular}{|c|c|c|c|c|}
\hline Faktörler & Madde Sayısı & Faktör Yüklerinin Aralığı & $\begin{array}{l}\text { Açıklanan } \\
\text { Varyans (\%) }\end{array}$ & $\begin{array}{l}\text { Cronbach } \\
\text { Alpha }(\alpha)\end{array}$ \\
\hline Kariyer Uyum Yetenekleri & 19 & ,601 - , 854 & 64,425 & $.88,9$ \\
\hline Kaygı & 3 & , 699 - 747 & 12,104 & $.71,5$ \\
\hline Kontrol & 5 & ,590 - 710 & 14,207 & $.79,2$ \\
\hline Merak & 5 & 601 - 746 & 14,606 & $.81,6$ \\
\hline Güven & 6 & 671 - ,854 & 21,245 & $.84,4$ \\
\hline
\end{tabular}

\section{KMO: ,814, Barlett: 2745,265; df=159; $p=, 000$}

Faktör analizi sonucunda 19 ifadeden oluşan 4 alt boyut bulunmuştur. Boyutlarda yer alan ifadelerin faktör yüklerinin ağırlığı Tablo 2'de gösterilmiştir. Kariyer uyum yeteneği ölçeği ve alt boyutlarının güvenilirlik analizi (Cronbach Alpha) sonuçlarına bakıldığında ise $0,70^{\prime}$ den yüksek olduğu görülmektedir. Cronbach Alpha $(\alpha)$ değeri 0,60 $\leq \alpha<0,80$ aralı̆̆ında ölçek oldukça güvenilirdir (Kalaycı, 2010: 405). Bu açıklamaya göre ölçek ve boyutlarının güvenilir olduğu sonucuna varılmaktadır.

\subsection{Anova Analizi Sonuçları}

Üniversite öğrencilerinin kariyer uyum yetenekleri ile tercih edilen bölümler arasındaki ilişkiyi belirlemek için kurulan hipottezi test etmek için Anova Analizi yapıımışıtır. Analiz sonuçları Tablo 3'de yer almaktadır.

Tablo 3: Kariyer Uyum Yeteneği Boyutları ile Tercih Edilen Bölümlerin Karşılaştırılması

\begin{tabular}{|c|c|c|c|c|c|c|}
\hline & $\begin{array}{l}\text { Tercih } \\
\text { Bölümler }\end{array}$ & $\begin{array}{l}\text { Öğrenci } \\
\text { Sayıları }\end{array}$ & Ortalama & $\begin{array}{l}\text { Standart } \\
\text { Sapma }\end{array}$ & $\mathbf{F}$ & $\mathbf{P}$ \\
\hline \multicolumn{7}{|c|}{ Kariyer Uyum Yeteneği } \\
\hline \multicolumn{6}{|c|}{ Faktörleri } & \\
\hline \multirow[t]{2}{*}{ Kaygı } & Halkla Illşkiler & 124 & 3,85 & 0,52 & 6,206 & 0,000 \\
\hline & Yerel Yönetimler & 106 & 3,89 & 0,59 & & \\
\hline \multirow[t]{3}{*}{ Kontrol } & İşletme Yönetimi & 192 & 3,13 & 0,76 & & \\
\hline & Halkla IIlşkiler & 124 & 2,93 & 0,76 & 2,186 & 0,090 \\
\hline & Yerel Yönetimler & 106 & 2,91 & 0,79 & & \\
\hline \multirow[t]{4}{*}{ Merak } & İşletme Yönetimi & 192 & 3,76 & 0,53 & & \\
\hline & Halkla illşkiler & 124 & 3,78 & 0,53 & 0,723 & 0,539 \\
\hline & Yerel Yönetimler & 106 & 3,88 & 0,60 & & \\
\hline & İşletme Yönetimi & 192 & 3,79 & 0,63 & & \\
\hline \multirow[t]{2}{*}{ Güven } & Halkla îlşkiler & 124 & 3,65 & 0,66 & 1,878 & 0,034 \\
\hline & Yerel Yönetimler & 106 & 3,70 & 0,69 & & \\
\hline
\end{tabular}

Tablo 3'te kariyer uyum yetenekleri faktörlerinin bölüm tercihi değişkenine göre Anova sonuçları gösterilmektedir. Araştırmaya katılan ögrencilerin tercih ettikleri bölümlerin kariyer uyum yeteneği boyutları ile karşılaştırması için yapılan Anova testi sonrasında tercih ettikleri bölümlere göre öğrencilerin cevapları arasında anlamlı fark bulunmuştur. 
Bu sonuçlardan hareketle katılımcıların kariyer uyum yetenekleri faktörleri ile tercih ettiği bölümler arasında farklılıklar tespit edilmiştir. Farkıı̆̆ın nerden kaynaklandığını belirlemeye yönelik Tukey testi sonuçlarına göre Yerel Yönetimler bölümü öğrencilerinin Halkla ílişkiler bölümü öğrencilerine, Halkla İlişkiler bölümü öğrencilerinin ise İşletme Yönetimi bölümü öğrencilerine kıyasla daha fazla kaygı taşıdıklarını ifade etmek mümkündür.

Diğer taraftan Güven boyutu ile de anlamlı bir fark bulunmuştur. Yine burada yapılan Tukey testi sonuçlarına göre ise İ̧̧letme Yönetimi bölümünün diğer iki bölüme göre daha fazla güven duyduğu görülmüştür. Çıkan sonuçlara göre $\mathrm{H} 1$ hipotezi kabul edilmiştir.

Üniversite öğrencilerinin cinsiyetleri ve gelir düzeyleri ile kariyer uyum yetenekleri arasındaki ilişkisiyi belirlemek için kurulan hipotezleri test amacıyla yapılan T-Testi ve Anova analizlerinin sonuçları Tablo 4 ve Tablo 5 'te yer almaktadır.

\section{Tablo 4: Kariyer Uyum Yeteneği Ortalamaları İle Cinsiyet Karşılaştırmasına Yönelik T Testi Tablosu}

\begin{tabular}{l|llll}
\hline Cinsiyet & $\mathbf{N}$ & Kariyer uyum yeteneği & $\mathbf{T}$ & $\mathbf{P}$ \\
Erkek & 204 & ortalaması & & \\
Kadın & 218 & 3,88 & $-2,314$ &, 000
\end{tabular}

Tablo 4'te verilen T testi sonuçlarına bakıldığında araştırmaya katılanların kariyer uyum yeteneği ortalamaları cinsiyete göre anlamlı fark bulunmuştur. Ortalama değerlerin erkeklerde, kadınlara göre daha yüksek bir değere sahip olduğu görülmüştür. H3 hipotezi kabul edilmiştir.

Tablo 5: Kariyer Uyum Yetenekleri İle Gelir Düzeyi Arasında Anavo Sonuçları

\begin{tabular}{|c|c|c|c|c|c|c|}
\hline Faktörler & GELİR DÜZEYLERi & ÖĞRENCI SAYILARI & ORTALAMA & $\begin{array}{l}\text { STANDART } \\
\text { SAPMA }\end{array}$ & $\mathbf{F}$ & $\mathbf{P}$ \\
\hline \multirow{4}{*}{ Kaygı } & 1603 TL ve altı & 71 & 3,67 & 0,84 & \multirow{4}{*}{2,315} & \multirow{4}{*}{0,024} \\
\hline & $1604-2000 \mathrm{TL}$ & 113 & 3,83 & 0,71 & & \\
\hline & $2001-3000$ TL & 150 & 3,93 & 0,54 & & \\
\hline & 3001 TL ve üzeri & 88 & 3,88 & 0,67 & & \\
\hline \multirow{4}{*}{ Kontrol } & 1603 TL ve altı & 71 & 3,79 & 0,64 & \multirow{4}{*}{1,875} & \multirow{4}{*}{0,145} \\
\hline & $1604-2000 \mathrm{TL}$ & 113 & 3,65 & 0,65 & & \\
\hline & $2001-3000 \mathrm{TL}$ & 150 & 3,70 & 0,69 & & \\
\hline & 3001 TL ve üzeri & 88 & 3,92 & 0,65 & & \\
\hline \multirow{4}{*}{ Merak } & 1603 TL ve altı & 71 & 3,11 & 0,58 & \multirow{4}{*}{1,780} & \multirow{4}{*}{0,029} \\
\hline & $1604-2000 \mathrm{TL}$ & 113 & 3,18 & 0,65 & & \\
\hline & $2001-3000$ TL & 150 & 3,25 & 0,68 & & \\
\hline & 3001 TL ve üzeri & 88 & 3,45 & 0,63 & & \\
\hline \multirow{4}{*}{ Güven } & 1603 TL ve altı & 71 & 3,45 & 0,48 & \multirow{4}{*}{0,988} & \multirow{4}{*}{0,254} \\
\hline & $1604-2000 \mathrm{TL}$ & 113 & 3,62 & 0,62 & & \\
\hline & 2001 - $3000 \mathrm{TL}$ & 150 & 3,12 & 0,54 & & \\
\hline & 3001 TL ve üzeri & 88 & 3,11 & 0,47 & & \\
\hline
\end{tabular}

Araştırmaya katılanların gelir düzeyleri ile kariyer uyum yetenekleri boyutları arasında farklılık olup olmadığına ilişkin Anova ve Tukey testi sonuçları tablo 5'te yer almaktadır. Bu sonuçlardan yola çıkarak kariyer uyum yeteneklerinden kaygı ve merak boyutunda farklılık tespit edilmiştir. Farklılığın kaynağını anlamaya yönelik yapılan Tukey testi sonuçlarına göre ise 1601-2000 gelire sahip olanların 3001 ve üzeri gelire sahip olanlara göre daha fazla kaygıya sahip olduklarını söylemek mümkündür. Aynı şekilde merak boyutu için farklılığı anlamaya yönelik yapılan Tukey testinde ise farklılığın 2001-3000 gelirine sahip olanların 1603 ve altı gelire sahip olanlara göre farklılık gösterdiği görülmüştür. Diğer iki boyut olan Güven ve Kontrol ile ilgili farkılık gözlenmemiştir. Kaygı ve Merak boyutuyla ilgili farklılık gözlendiğinden dolayı $\mathrm{H} 2$ hipotezimiz kabul edilmiştir.

\section{SONUÇ}

Bu çalışmada kariyer uyum yetenekleri ile tercih edilen bölüm ve demografik değişkenlerden cinsiyet ve gelir düzeyi değişkenlerinin farklılaşıp farklılaşmadığının incelenmesi amaçlanmıştır. Cinsiyete yönelik yapılan T-testi sonucuna göre farklıık görülmüştür. Yapılan literatür taramalarında ise farklıık gösterdiği ve göstermediği çalışmalara ulaşılıı̧ıı. Bu çalışmada ise erkeklere ait ortalamanın bayanlara göre daha yüksek çıkmış olması erkeklerin kariyer uyum yeteneklerinin bayanlara göre daha yüksek olduğunu ifade etmektedir.

Araştırmada düşük gelir seviyesine sahip bireylerin kaygı seviyelerinin yüksek olması kariyer uyum yeteneğine olumsuz etki edeceği yönünde bulgulara ulaşılmıştır 645-159. Bu beklenen bir sonuçtur, çünkü gelir düzeyi düşük bireylerin esneklikleri geliri yüksek bireylere göre daha düşük olması kaçınılmazdır. Bu sebeple kolay iş değiştirememe ve yeni iş şartlarına bağlı uyum yeteneğinin gelişmesine yeterince zemin hazırlayamama durumu söz konusudur. Bunun yanında merak boyutunda ise yüksek gelir gurubu anlamlı olarak farklılaşmıştır. Maddi 
güce sahip olmak yeniliğe açık olmanın da yolunu açma ihtimalinden yüksek gelir grubuna ait bireyler hem daha meraklı hem de yenilikten dolayı değişime uyum sağlama yeteneğine yatkın olabileceği söylenebilir.

Tercih edilen bölümlere göre bakıldığında ise Kaygı ve Güven boyutlarında farklılık görülmüştür. Kaygı boyutunda Yerel Yönetimler bölümü öğrencilerinin diğer iki bölüme göre daha fazla kaygı duyduğu sonucuna ulaşılmıştır. Bu durum mezun öğrencilerin daha ziyade kamu da iş bulma durumundan kaynaklandığı düşünülebilir. Toplumda bilinenin aksine işletme yönetimi bölümü öğrencilerinin 3 bölümden en az kaygıya sahip olması araştırmanın diğer dikkat çekici sonucudur. Özel sektör ve kamu da çalışabilme ihtimali mezunların daha az kaygı duymalarına sebep olmaktadır. Güven boyutunda ise işletme yönetimi bölümünü tercih edenlerin farklılığa sebep olduğu görülmektedir. Yukarıda da ifade edildiği gibi bu bölümden mezun öğrencilerin her alanda iş başvurusu yapabilme imkanları, bireyleri daha fazla güven duymasına yani karşılaşabileceği sorunları çözebilme yeteneğini kendisinde görmesi olarak açıklanabilir.

\section{KAYNAKLAR}

Arpat, B., Yeşil, Y. (2017). Analyzing the reasons of occupational health and safety training students' profession choice: a research at Pamukkale University - Honaz Vocational School., European Scientific Journal, May Special/Edition, 182-191.

Arthur, M. B., Lawrence B. S. (1984). Perspectives on environment and career: an introduction. Journal of Occupational Behaviour, 5, 1-8.

Aydın, Z. B. (2007). Faktör analizi yardimiyla performans ölçütlerinin boyutlarinin ortaya konulmasi. 8. Türkiye Ekonometri ve İstatistik Kongresi. Malatya: İnönü Üniversitesi

Çelik, Ö. (2017). Eleştirel düşünme becerilerinin kariyer uyum yeteneklerine etkisi. Yayınlanmamış Yüksek Lisans Tezi, Süleyman Demirel Üniversitesi, Sosyal Bilimler Enstitüsü, Isparta.

Decenzo, D. A., Robbins, S. P. (1996). Human resource management (5th Edition). ABD: J. Wiley \& Sons.

Dündar, G. (2013). Kariyer geliştirme. Sadullah, Ö., Uyargil, C., Acar, A.C. vd., İnsan Kaynakları Yönetimi (Yenilenmiş 6. Baskı) (s. 267-299). İstanbul: Beta Basım Yayım Dağıtım.

Erdoğan, B. Z. (2008). Bireyden profesyonele: kariyere ilk adim. Bursa: Ekin Yayınları.

Genç, M. (2016). Öğrencilerin kişisel gelişim yönelimlerinin kariyer uyum yeteneklerine etkisi: Ağrı İbrahim Çeçen Üniversitesi örneği. Yayınlanmamış Yüksek Lisans Tezi, Karabük Üniversitesi, Sosyal Bilimler Enstitüsü, Karabük.

Kalaycı, Ş. (Ed.). (2010). SPSS uygulamali çok değişkenli istatistik teknikleri (5. Baskı). Ankara: Asil Yayın Dağıtım.

Kavi, E., Kaya, A. (2018). İstanbul'da öğrenim gören üniversite öğrencilerinin kariyer uyum yeteneklerine yönelik bir araştirma. Uluslararası Medeniyet Çalışmaları Dergisi, 3 (1), 104-116.

Kanten, S. (2012). Kariyer uyum yetenekleri ölçeği: geçerlilik ve güvenilirlik çalişmasi. Süleyman Demirel Üniversitesi Sosyal Bilimler Enstitüsü Dergisi, 16, 191-205.

Mercan, N. (2016). Psikolojik sermayenin kariyer uyum yeteneği ile ilişkisine yönelik bir araştirma. Global Business Research Congress (GBRC), PressAcademia Procedia, 434-442.

Öge, S., Karasoy, H. A. (2016). İnsan kaynaklari yönetimi. Konya: Eğitim Kitabevi.

Perkmen, S. (2009). 21. yüzyilda kariyer seçimi. İstanbul: Profil Yayıncılık.

Savickas, M. L. (1997). Career adaptability: an integrative construct for life-span, life-space theory. The Career Development Quarterly, 45, 247-259.

Savickas, M. L., Porfeli, E. J. (2012). The career adapt-abilities scale: construction, reliability, and measurement equivalence across 13 countries. Journal of Vocational Behavior, 80, 661-673.

TDK (2018). http://www.tdk.gov.tr/index.php?option=com gts\&arama=gts\&guid=TDK.GTS.5af2fbd2950aa9.38027475. Erişim Tarihi: 27.04.2018

Vianen, A. E. M., Klehe, U., Koen, J., Dries, N. (2012). Career adaptabilities scale Netherlands form: psychometric properties and relationships to ability, personality, and regulatory focus. Journal of Vocational Behavior, 80, 716-724.

Woodd, M. (1999). The move towards a different career pattern: are women better prepared then men for a modern career?. Career Development International, 14(1), 21-28.

Yazıcı, R. (1987). İnsan ilişkileri ve personel yönetimi. Ankara: Semih Ofset.

Zikic, J, Klehe, U. C. (2006). Job loss as a blessing in disguise: the role of career exploration and career planning in predicting reemployment quality. Journal of Vocational Behavior. 69, 391-409.

Zorver, C. E., Owenn, F. K. (2014). Kariyer uyumu ve iyimserliği ölçeği'nin geliştirilmesi. International Journal of Human Sciences, 11(2), 314331. 